\title{
VIEWPOINT
}

\section{High-Dose Intravenous Ascorbic Acid: Ready for Prime Time in Traumatic Brain Injury?}

\author{
Stefan W. Leichtle ${ }^{1 *}$ (D) Anand K. Sarma ${ }^{2}$, Micheal Strein ${ }^{3}$, Vishal Yajnik ${ }^{4}$, Dennis Rivet ${ }^{5}$, Adam Sima ${ }^{6}$ \\ and Gretchen M. Brophy ${ }^{3,5}$
}

(C) 2019 Springer Science+Business Media, LLC, part of Springer Nature and Neurocritical Care Society

\begin{abstract}
Traumatic brain injury (TBI) is one of the leading public health problems in the USA and worldwide. It is the number one cause of death and disability in children and adults between ages 1-44. Despite efforts to prevent TBIs, the incidence continues to rise. Secondary brain injury occurs in the first hours and days after the initial impact and is the most effective target for intervention. Inflammatory processes and oxidative stress play an important role in the pathomechanism of TBI and are exacerbated by impaired endogenous defense mechanisms, including depletion of antioxidants. As a reducing agent, free radical scavenger, and co-factor in numerous biosynthetic reactions, ascorbic acid (AA, vitamin C) is an essential nutrient that rapidly becomes depleted in states of critical illness. The administration of high-dose intravenous (IV) AA has demonstrated benefits in numerous preclinical models in the areas of trauma, critical care, wound healing, and hematology. A safe and inexpensive treatment, high-dose IV AA administration gained recent attention in studies demonstrating an associated mortality reduction in septic shock patients. High-quality data on the effects of high-dose IV AA on TBI are lacking. Historic data in a small number of patients demonstrate acute and profound AA deficiency in patients with central nervous system pathology, particularly TBI, and a strong correlation between low AA concentrations and poor outcomes. While replenishing deficient AA stores in TBI patients should improve the brain's ability to tolerate oxidative stress, high-dose IV AA may prove an effective strategy to prevent or mitigate secondary brain injury due to its ability to impede lipid peroxidation, scavenge reactive oxygen species, suppress inflammatory mediators, stabilize the endothelium, and reduce brain edema. The existing preclinical data and limited clinical data suggest that high-dose IV AA may be effective in lowering oxidative stress and decreasing cerebral edema. Whether this translates into improved clinical outcomes will depend on identifying the ideal target patient population and possible treatment combinations, factors that need to be evaluated in future clinical studies. With its excellent safety profile and low cost, high-dose IV AA is ready to be evaluated in the early treatment of TBI patients to mitigate secondary brain injury and improve outcomes.
\end{abstract}

Keywords: Traumatic brain injury, Secondary brain injury, Oxidative stress, Antioxidant, Free radical scavenger, Vitamin C, Ascorbic acid

\footnotetext{
*Correspondence: stefan.leichtle@vcuhealth.org

${ }^{1}$ Division of Acute Care Surgical Services, Department of Surgery, Virginia

Commonwealth University School of Medicine, Richmond, USA

Full list of author information is available at the end of the article
}

\section{至 Springer}




\section{Traumatic Brain Injury}

Traumatic brain injury (TBI) is one of the leading public health problems in the USA and worldwide, resulting in 2.8 million Emergency Department (ED) visits and 56,000 deaths per year [1]. Already the leading cause of death and disability in children and adults between ages 1-44, the incidence of TBI continues to rise [1]. In addition to the direct brain injury caused by traumatic impact, secondary brain injury due to local tissue ischemia, edema, metabolic changes, and damage from reactive oxygen species (ROS) results in further neurologic deterioration [2-10]. Current treatment strategies to mitigate secondary brain injury are limited to the optimization of a patient's general clinical condition, including maintenance of adequate cerebral perfusion pressures, management of intracranial hypertension, and prevention of hypotension, hypoxia, and seizures. No proven, effective treatment exists to provide neuroprotection in the acute phase or to promote neuroregeneration in the delayed therapeutic window after TBI $[11,12]$.

\section{Ascorbic Acid (Vitamin C)}

Ascorbic acid (AA, vitamin C) is an essential nutrient that functions as an important reducing agent, free radical scavenger, and co-factor in numerous biosynthetic reactions [13-15]. The recommended dietary allowance for AA for healthy individuals is $75 \mathrm{mg}$ and $90 \mathrm{mg}$ per day for women and men, respectively, though some guidelines recommend higher doses of up to $200 \mathrm{mg}$ per day [16]. AA is readily absorbed from the intestinal tract when consumed orally, and higher doses above $1000 \mathrm{mg}$ per day are excreted renally $[17,18]$. While oral administration of $\mathrm{AA}$ is adequate to maintain homeostasis, intake of substantially higher doses is required to achieve supranormal, ROS-scavenging AA concentrations, particularly in states of acute injury and critical illness $[18,19]$.

While not universally defined, normal AA concentrations range from $21 \mu \mathrm{mol} / \mathrm{L}(0.37 \mathrm{mg} / \mathrm{dL})$ to $100 \mu \mathrm{mol} / \mathrm{L}$ $(1.76 \mathrm{mg} / \mathrm{dL})[17,20,21]$. In a small cohort of healthy volunteers, mean peak plasma concentrations of AA reached $134.8 \pm 20.6 \mu \mathrm{mol} / \mathrm{L}$ after oral administration of $1250 \mathrm{mg}$ AA. In contrast, IV administration of this dose resulted in peak plasma concentrations of $885 \pm 201.2 \mu \mathrm{mol} / \mathrm{L}$. Predicted maximum peak plasma concentrations were no more than $220 \mu \mathrm{mol} / \mathrm{L}$ with oral administration of $3000 \mathrm{mg}$ AA every $4 \mathrm{~h}$, but reached $1760 \mu \mathrm{mol} / \mathrm{L}$ for IV administration of this dose [22]. Based on these and other data, any effective AA treatment regimen for critically ill patients must be administered IV rather than orally. In 20 critically ill patients with multiple organ dysfunction, $2000 \mathrm{mg}$ AA per day given IV restored normal AA plasma concentrations, but only a daily dose of $10,000 \mathrm{mg}$ IV AA elevated plasma AA concentrations to above $1000 \mu \mathrm{mol} / \mathrm{L}$, the optimal concentration for free radical scavenging effects [20, 22-24]. In 24 critically ill patients with sepsis, Fowler et al. demonstrated that IV administration of $200 \mathrm{mg} / \mathrm{kg}$ per day (as compared to $50 \mathrm{mg} / \mathrm{kg} / \mathrm{d}$ ) in four bolus doses effectively and consistently elevated steady-state plasma concentrations to above $1000 \mu \mathrm{mol} / \mathrm{L}$ within $24 \mathrm{~h}$ of the first dose [23]. Therefore, a treatment regimen of $50 \mathrm{mg} / \mathrm{kg}$ IV AA given every $6 \mathrm{~h}$ (for a total of $200 \mathrm{mg} / \mathrm{kg}$ per day) is most likely to result in consistently supra-normal, ROS-scavenging plasma AA concentrations in critically ill patients. In its oxidized form dehydroascorbic acid (DHA), AA is actively and preferentially transported into the central nervous system (CNS), crossing the blood-brain barrier (BBB) by facilitative transport. This mechanism results in substantially higher AA concentrations in the CNS than in plasma $[25,26]$. Therefore, plasma concentrations of AA may not be reflective of CNS concentrations, but their correlation is unclear.

AA administration has few clinically relevant adverse effects. As a highly water-soluble compound, AA is readily excreted through kidneys and urine, limiting the potential for systemic toxicity. Therefore, direct renal toxicity and formation of oxalate stones is the most frequently noted concern with high-dose AA treatment [27]. Healthy individuals did not experience relevant adverse effects or laboratory abnormalities with daily doses of $7500 \mathrm{mg}$ IV for 6 days [28], critically ill patients tolerated daily administration of $4500 \mathrm{mg}$ IV for 28 days [29], and even higher doses were found to be safe in phase-1 cancer and sepsis trials [23, 30-32]. Occasionally reported adverse effects include gastrointestinal discomfort and headache, but overall, high-dose IV AA is regarded to have a good safety profile with a low risk of toxicity over a wide range of doses.

\section{Ascorbic Acid Deficiency in Critical Illness, Trauma, and Burns}

Critical illness is marked by depletion of AA stores [3335]. The administration of antioxidants, including AA, in states of critical illness has re-emerged as a promising area for study due to significant success in small patient cohorts with septic shock $[23,36]$ and supported by basic science research in trauma, wound healing, and hematology [37-40]. Traumatic injuries, acute infection, and critical illness result in a pro-inflammatory state marked by dysregulation of the immune system, high levels of ROS, and capillary leak due to endothelial damage and increased permeability [41-43]. Antioxidants, most importantly AA, have the potential to influence these pathomechanisms.

In rodent models of bacterial- or endotoxin-induced sepsis, AA administration attenuated the inflammatory 
response and decreased microvascular permeability, decreasing their risk for organ dysfunction and mitigating lung damage $[44,45]$. Clinically, lung-protective effects of AA were described by Nathens et al. [29] in a cohort of severely injured trauma patients in the ICU setting. IV administration of $1000 \mathrm{mg}$ AA three times per day, enterally supplemented by $1000 \mathrm{IU}$ alpha-tocopherol, resulted in modest but significant reduction of pulmonary complications. Berger and colleagues studied a mix of antioxidant supplements (2700 mg AA per day, and selenium, zinc, and vitamin B1) in a randomized trial involving a heterogenous surgical population of 200 patients, 30\% of which were trauma patients. This antioxidant cocktail reduced C-reactive protein (CRP) concentrations, but had no measurable effect on organ dysfunction [46].

In a porcine model of severe polytrauma and hemorrhage, Reynolds et al. demonstrated that AA supplementation mitigated end-organ damage on histopathologic assessment, severity of lung injury, and decreased levels of the pro-inflammatory markers interleukin (IL)-1 $\beta$, IL-8, TNF $\alpha$, plasminogen activator inhibitor-1, and tissue factor [37]. While similar effects have been corroborated in numerous prior small animal studies, there are no conclusive data from clinical trials in (poly)trauma patients. In animal and clinical studies of severe burn injuries, AA administration decreases capillary leak and significantly reduces resuscitation fluid requirements [47-49]. Doses evaluated ranged from $15 \mathrm{mg} / \mathrm{kg} / \mathrm{h}$ in animal studies to $66 \mathrm{mg} / \mathrm{kg} / \mathrm{h}$ in clinical trials. Similar to other fields of study, animal studies far outnumber clinical trials, and results in the clinical setting are less impressive than in animal models.

\section{Ascorbic Acid in TBI}

Oxidative stress is an important contributor in the pathogenesis of secondary brain injury [2, 4-10]. Cellular defense mechanisms against this damage are impaired in acute illness due to the depletion of free radical scavengers such as AA [7, 8, 34, 50, 51]. Figure 1 shows one of the proposed mechanisms of neuroprotection of highdose IV AA in TBI. In a small cohort of patients with TBI and hemorrhagic stroke, plasma concentrations of AA were found to be low and inversely correlated with injury severity. In this 2001 study, 13 patients with TBI had significantly lower plasma concentrations of AA $(29 \pm 8 \mu \mathrm{mol} / \mathrm{L})$ than healthy controls $(52 \pm 8 \mu \mathrm{mol} / \mathrm{L})$, and AA plasma concentrations inversely correlated with hemorrhage size [34]. In a 1984 study of AA concentrations in the cerebrospinal fluid (CSF) of 41 patients with neurologic disorders, five patients with TBI had lower AA concentrations than all other patients, including those with hydrocephalus and seizure disorders. AA concentrations in the CSF of patients with head and cervical trauma were $77 \pm 56 \mu \mathrm{mol} / \mathrm{L}$ compared to the reference cohort with an average of $203 \pm 49 \mu \mathrm{mol} / \mathrm{L}$ [7].

These few clinical studies on AA deficiency in patients with TBI are in contrast to more robust literature in animal models. In rodent models of ischemic stroke, DHA exhibited neuroprotective effects in both pre-treated animals and those that received DHA after the ischemic insult $[52,53]$. In a rodent model of TBI, combined administration of moderate doses of $\mathrm{AA}$ and vitamin $\mathrm{E}$ resulted in improved cellular defense mechanism and confirmed depletion of important antioxidants after TBI [54]. In a rodent model of spinal cord injury, high-dose AA administration significantly reduced tissue necrosis and improved functional performance in rats [55].

In addition to its potent action as free radical scavenger, AA may stabilize the endothelium and promote integrity of the BBB. Following the mechanical impact of TBI, ischemia, reperfusion, and the imbalance between diminished protective factors such as free radical scavengers and NF-E2 related factor-2 $[56,57]$ and upregulated damaging factors such as

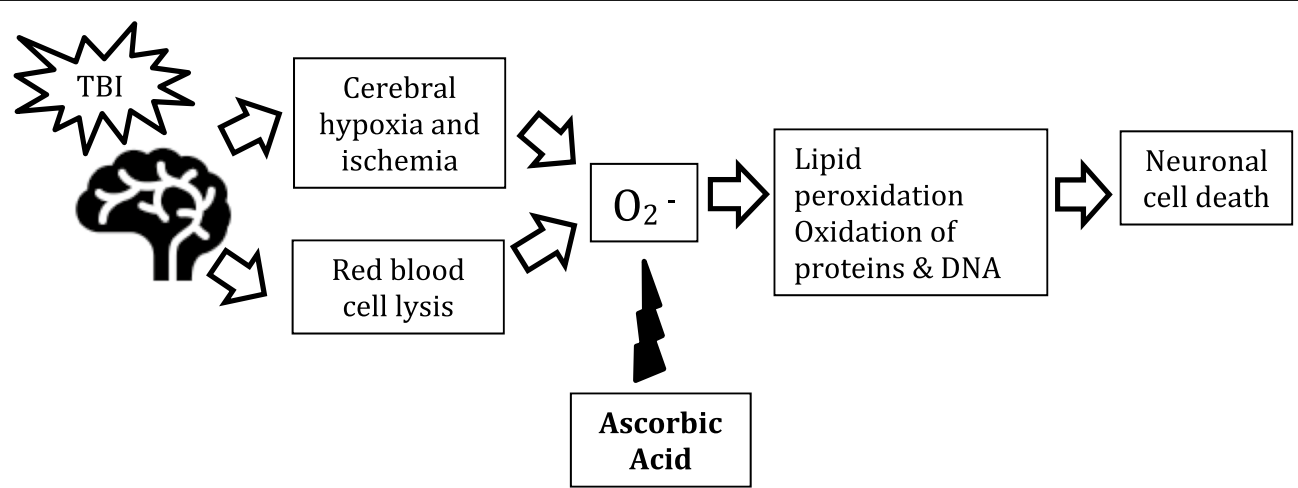

Fig. 1 Proposed reactive oxygen-scavenging-mechanism of high-dose IV ascorbic acid in TBI. TBI, traumatic brain injury; $\mathrm{O}_{2}^{-}$, reactive oxygen species; DNA, deoxyribonucleic acid 
metalloproteinase (MMP)-9 lead to disruption of transmembrane tight junction proteins in the basal lamina of the BBB [55, 56, 58-61]. ROS cause cell damage through lipid peroxidation of the fatty acids in cell and mitochondrial membranes [62, 63]. With its potent antioxidant properties, high-dose AA may mitigate this cascade [57, 61].

Unfortunately, clinical data on the therapeutic use of antioxidants to date have been inconclusive or disappointing [64]. Strategies that showed promise in animal models and preclinical testing such as mitochondrial protection, progesterone administration, anticonvulsants, and several antioxidant strategies like resveratrol, flavonoids, and omega- 3 polyunsaturated fatty acids have not translated into successful clinical trials [65-68]. Compared to other states of critical illness, there is a paucity of data on the clinical use of AA in TBI. Table 1 provides an overview of studies on AA in patients with critical illness in the last two decades, fewer than $10 \%$ of which included patients with severe TBI. In the only randomized controlled trial on AA in TBI, high-dose (10,000 mg days 1 and 4; $4000 \mathrm{mg}$ days 5 through 7) IV AA administration in 23 patients resulted in decreased perilesional edema on CT imaging $(p=0.01)$, but no improvement in outcomes [69]. Due to the dosing regimen, it is unlikely that ROS-scavenging plasma levels were reached in this trial.
The most appropriate dose of AA in TBI is not known. However, higher doses have shown benefit in other critically ill patients without causing harm. Therefore, moderate to high doses of IV AA (10,000-20,000 mg per day) may be required to replenish deficient $A A$ stores in patients with TBI experiencing oxidative stress several days after injury. Due to the limited data on prevalence and extent of AA deficiency in TBI, it is unclear if and to what degree this would translate into protection from secondary brain injury and improved clinical outcomes. Contemporary data on AA concentrations in plasma and CSF of patients with varying degrees of TBI may allow for the identification of a high-risk patient population that would benefit most from AA repletion and is currently being studied by our research group. Based on animal data [70,71], the aging brain may be particularly susceptible to oxidative damage due to an inability to take up and mobilize AA. Clinically, lower CNS/plasma AA ratio in older adults compared to younger patients with TBI may indicate a high-risk patient group for further study.

Administration of high-dose IV AA $(\geq 200 \mathrm{mg} / \mathrm{kg}$ per day) would harness the anti-inflammatory, ROS-scavenging, and cell membrane-stabilizing properties of AA. These mechanisms of action may be most beneficial in patients with significant cerebral edema and elevated intracranial pressure when administered within hours

Table 1 Pertinent clinical trials of IV ascorbic acid in the last two decades

\begin{tabular}{|c|c|c|c|c|c|}
\hline References & Design & Type of injury & Patients & Ascorbic acid dosing $^{a}$ & Results \\
\hline Marik et al. 2017 [36] & $\begin{array}{l}\text { Retrospective before- } \\
\text { after }\end{array}$ & $\begin{array}{l}\text { Severe sepsis/septic } \\
\text { shock }\end{array}$ & 94 adults & $6 \mathrm{~g} \times 4$ days $^{\mathrm{b}}$ & Mortality reduction \\
\hline Fowler et al. 2014 [23] & $\begin{array}{l}\text { Randomized double- } \\
\text { blind placebo- } \\
\text { controlled }\end{array}$ & $\begin{array}{l}\text { Severe sepsis (mostly } \\
\text { respiratory) }\end{array}$ & 24 adults & $\begin{array}{l}50 \mathrm{mg} / \mathrm{kg} / \mathrm{day} \\
\text { or } 200 \mathrm{mg} / \mathrm{kg} / \\
\text { day } \times 4 \text { days }\end{array}$ & $\begin{array}{l}\text { Reduced SOFA scores } \\
\text { and inflammatory } \\
\text { markers }\end{array}$ \\
\hline $\begin{array}{l}\text { Razmkon et al. } 2011 \\
\text { [69] }\end{array}$ & $\begin{array}{l}\text { Randomized double- } \\
\text { blind placebo- } \\
\text { controlled }\end{array}$ & $\mathrm{TBI}$ with $\mathrm{GCS} \leq 8$ & $\begin{array}{l}100 \text { adults (four } \\
\text { groups, } 23 \text { patients } \\
\text { received high-dose } \\
\text { AA) }\end{array}$ & $\begin{array}{l}10 \mathrm{~g} \text { in day } 1,10 \mathrm{~g} \text { on } \\
\text { day } 4,4 \mathrm{~g} \text { daily for } \\
\text { three more days }\end{array}$ & $\begin{array}{l}\text { High-dose AA decreased } \\
\text { perilesional edema on } \\
\text { head CT }\end{array}$ \\
\hline Barbosa et al. 2009 [49] & $\begin{array}{l}\text { Randomized double- } \\
\text { blind placebo- } \\
\text { controlled }\end{array}$ & $\begin{array}{l}\text { Burns with TBSA } \\
10-50 \% \text {, at least } \\
\text { partial thickness }\end{array}$ & 32 children & $\begin{array}{l}\text { Up to } 2.7 \mathrm{~g} \text { daily } \\
\text { ( } 1.5 \times \text { upper daily } \\
\text { intake based on age) } \\
\text { for } 5 \text { days }\end{array}$ & $\begin{array}{l}\text { Decreased lipid per- } \\
\text { oxidation and faster } \\
\text { wound healing }\end{array}$ \\
\hline Berger 2008 [18] & $\begin{array}{l}\text { Randomized double- } \\
\text { blind placebo- } \\
\text { controlled }\end{array}$ & $\begin{array}{l}\text { Complex cardiac sur- } \\
\text { gery, major trauma, } \\
\text { or SAH }\end{array}$ & $\begin{array}{l}200 \text { adults (21 with } \\
\text { SAH) }\end{array}$ & $\begin{array}{l}2.7 \mathrm{~g} \text { for two days, } 1.6 \mathrm{~g} \\
\text { for three days }\end{array}$ & $\begin{array}{l}\text { Decreased inflammatory } \\
\text { response (CRP) }\end{array}$ \\
\hline Nathens et al. 2002 [29] & $\begin{array}{l}\text { Randomized prospec- } \\
\text { tive trial }\end{array}$ & $\begin{array}{l}\text { Trauma patients, } \\
\text { excluding isolated } \\
\text { TBl and patients with } \\
\text { GCS } \leq 6\end{array}$ & 595 patients & $\begin{array}{l}1 \mathrm{~g} \text { TID for up to } \\
28 \text { days or length of } \\
\text { ICU stay }\end{array}$ & $\begin{array}{l}\text { Decreased risk for MSOF, } \\
\text { shorter ICU stay }\end{array}$ \\
\hline Tanaka et al. 2000 [47] & $\begin{array}{l}\text { Randomized prospec- } \\
\text { tive trial }\end{array}$ & Burns with TBSA $\geq 20 \%$ & 37 adults & $\begin{array}{l}66 \mathrm{mg} / \mathrm{kg} / \mathrm{hr} \text { as } \\
\text { continuous infusion } \\
\text { for } 24 \mathrm{~h}\end{array}$ & $\begin{array}{l}\text { Decreased IVF require- } \\
\text { ments and improved } \\
\text { respiratory function }\end{array}$ \\
\hline
\end{tabular}

CRP C-reactive protein, CT computed tomography, GCS Glasgow Coma Scale, IVF intravenous fluid, MSOF multi-system organ failure, SAH subarachnoid hemorrhage, SOFA sequential organ failure assessment, TBI traumatic brain injury, TBSA total body surface area

a Only AA dosing shown

${ }^{\mathrm{b}}$ AA was part of a treatment regimen including other medications 
of TBI. Many animal studies that examined the administration of antioxidant cocktails and vitamins, including AA, did not employ such high doses. However, these higher doses are required in critically ill patients to reliably achieve protective antioxidant concentrations and beneficial clinical outcomes, as recently demonstrated in patients with septic shock [23,36].

Prehospital administration of IV AA to patients with (suspected) TBI could be even more effective in mitigating damage to the blood-brain barrier and mitochondria of the brain parenchyma, which starts to occur within minutes of the traumatic event $[62,63]$. However, prehospital administration of AA would add substantial complexity to a clinical trial; challenges would include the correct identification of TBI as the cause for altered mental status in (poly-)trauma patients, the possible lack of knowledge of comorbidities that could increase the risk profile of high-dose AA administration, and the logistical challenge of storing solutions of high-dose AA on ambulances. For the latter, promising data exist on the stability of solutions containing low- to moderate AA doses [72]. If results of a solid clinical (in-hospital) trial indicate therapeutic efficacy of AA in TBI, studies on the prehospital administration of AA for TBI in select patient populations should certainly be considered.

\section{Limitations and Challenges}

Primary TBI and ROS-mediated damage to brain parenchyma and the BBB occur at the time of injury and shortly thereafter $[62,63]$, making administration of neuroprotective agents challenging. Even in mature trauma systems, the first dose of AA may realistically not occur until hours after injury rather than minutes after the initial traumatic event as in preclinical models. Therefore, the effect of high-dose AA will likely be of particular benefit in those with areas of substantial ischemic penumbra, cerebral edema, and elevated intracranial pressure. Additional benefit would be expected from the general effect of high-dose AA on the state of TBI-related critical illness.

In rodent models of $\mathrm{TBI}$, the oxidized form of $\mathrm{AA}$, DHA, is more effective in crossing the BBB [52] and concentration-dependent downregulation of AA transporters across the BBB might impede the accumulation of supra-normal, ROS-scavenging concentrations of AA in the CNS [73]. DHA is not currently FDA-approved and is only used in experimental models. However, the AA plasma concentrations that can be achieved with highdose IV administration will provide a steep plasma concentration gradient [74] ensuring uptake into the CNS. Lastly, both continuous and intermittent administration regimens of AA may need to be examined. In Fowler et al's phase I study on high-dose IV AA in patients with sepsis, doses of $200 \mathrm{mg} / \mathrm{kg}$ per day, given in four doses every $6 \mathrm{~h}$, rapidly led to plasma AA concentrations of $\geq 1000 \mu \mathrm{mol} / \mathrm{L}$ [23]. In de Grooth et al's study comparing low- vs. high-dose and intermittent vs. continuous administration of IV AA in septic patients, bolus dosing provided rapid plasma peak concentrations and continuous dosing was effective in achieving high steady-state concentrations [20]. For TBI patients in an ICU environment, both regimens of administration would be feasible.

\section{Conclusion}

Inflammatory processes, ROS, and endothelial dysfunction are well-established contributors to secondary brain injury. The promising results achieved with antioxidants and free radical scavengers in animal studies are in stark contrast to disappointing clinical results. Based on its mechanisms of action, animal data, and clinical results in critical illness, high-dose AA has exceptional potential to be an effective treatment strategy in the acute phase of TBI. It may be able to mitigate secondary brain injury due to its antioxidant, anti-inflammatory, and cell membrane-stabilizing properties, while the low adverse effect and cost profile of AA make it well suited for clinical studies in patients with TBI. A key challenge will be to identify the ideal TBI patient population that is most likely to benefit from this treatment strategy. Based on the existing data from related fields, patients with moderate to severe TBI, significant brain edema with elevated intracranial pressure, and the older adult population may represent ideal patient groups for high-dose IV AA in the acute setting. Clinical trials in such high-risk populations, rather than a more heterogenous patient group with TBI, may be the key to translating the promising animal data into actual improved patient outcomes. In summary, the existing ample animal and limited clinical data suggest that for the right patient population and at the appropriate dose, high-dose IV AA can benefit patients with TBI.

\section{Author details \\ 1 Division of Acute Care Surgical Services, Department of Surgery, Virginia Commonwealth University School of Medicine, Richmond, USA. ${ }^{2}$ Department of Neurology, Wake Forest School of Medicine, Winston-Salem, USA. ${ }^{3}$ Depart- ment of Pharmacotherapy and Outcomes Sciences, Virginia Commonwealth University School of Pharmacy, Richmond, USA. ${ }^{4}$ Division of Critical Care, Department of Anesthesiology, Virginia Commonwealth University School of Medicine, Richmond, USA. ${ }^{5}$ Department of Neurosurgery, Virginia Com- monwealth University School of Medicine, Richmond, USA. ${ }^{6}$ Department of Biostatistics, Virginia Commonwealth University, Richmond, USA.}

\section{Author Contributions}

This manuscript complies with all instructions to authors. Authorship requirements have been met by all authors, and the final manuscript was approved by all co-authors.

Conflict of interest

The authors declare that they have no conflict of interest. 


\section{Publisher's Note}

Springer Nature remains neutral with regard to jurisdictional claims in published maps and institutional affiliations.

Published online: 22 August 2019

\section{References}

1. Taylor CA, Bell JM, Breiding MJ, Xu L. Traumatic brain injury-related emergency department visits, hospitalizations, and deaths-United States, 2007 and 2013. MMWR Surveill Summ. 2017;66(9):1-16.

2. Dearden NM. Mechanisms and prevention of secondary brain damage during intensive care. Clin Neuropathol. 1998;17(4):221-8.

3. Jones PA, Andrews PJ, Midgley S, et al. Measuring the burden of second ary insults in head-injured patients during intensive care. J Neurosurg Anesthesiol. 1994;6(1):4-14.

4. Lok J, Leung W, Murphy S, Butler W, Noviski N, Lo EH. Intracranial hemorrhage: mechanisms of secondary brain injury. Acta Neurochir Suppl. 2011:111:63-9.

5. Ikeda Y, Long DM. The molecular basis of brain injury and brain edema: the role of oxygen free radicals. Neurosurgery. 1990;27(1):1-11.

6. Hall E, Braughler J. Central nervous system trauma and stroke: II. Physiological and pharmacological evidence for involvement of oxygen radicals and lipid peroxidation. Free Rad Biol Med. 1989:6(3):303-13.

7. Brau RH, García-Castiñeiras S, Rifkinson N. Cerebrospinal fluid ascorbic acid levels in neurological disorders. Neurosurgery. 1984;14(2):142-6.

8. Tyurin VA, Tyurina YY, Borisenko GG, et al. Oxidative stress following traumatic brain injury in rats: quantitation of biomarkers and detection of free radical intermediates. J Neurochem. 2002;75(5):2178-89.

9. Kontos HA, Povlishock JT. Oxygen radicals in brain injury. Central Nervous System Trauma. 1986;3(4):257-63.

10. Povlishock JT, Kontos HA. The role of oxygen radicals in the pathobiology of traumatic brain injury. Hum Cell. 1992;5(4):345-53.

11. Hutchinson PJ, Kolias AG, Timofeev IS, et al. Trial of decompressive craniectomy for traumatic intracranial hypertension. N Engl J Med. 2016;375(12):1119-30.

12. Andrews PJD, Sinclair HL, Rodriguez A, et al. Hypothermia for intracranial hypertension after traumatic brain injury. N Engl J Med. 2015;373(25):2403-12.

13. DePhillipo NN, Aman ZS, Kennedy MI, Begley JP, Moatshe G, LaPrade RF. Efficacy of vitamin C supplementation on collagen synthesis and oxidative stress after musculoskeletal injuries: a systematic review. Orthop J Sports Med. 2018;6(10):2325967118804544.

14. Biesalski HK, McGregor GP. Antioxidant therapy in critical care-is the microcirculation the primary target? Crit Care Med. 2007;35(9 Suppl):S577-583

15. Ellis GR, Anderson RA, Lang D, et al. Neutrophil superoxide anion-generating capacity, endothelial function and oxidative stress in chronic heart failure: effects of short- and long-term vitamin C therapy. J Am Coll Cardiol. 2000:36(5):1474-82.

16. Vanek VW, Borum P, Buchman A, et al. A.S.P.E.N. position paper: recommendations for changes in commercially available parenteral multivitamin and multi-trace element products. Nutr Clin Pract. 2012;27(4):440-91.

17. Levine M, Conry-Cantilena C, Wang Y, et al. Vitamin C pharmacokinetics in healthy volunteers: evidence for a recommended dietary allowance. Proc Natl Acad Sci USA. 1996;93(8):3704-9.

18. Berger MM. Vitamin C requirements in parenteral nutrition. Gastroenterology. 2009;137(5 Suppl):S70-78.

19. Long CL, Maull Kl, Krishnan RS, et al. Ascorbic acid dynamics in the seriously ill and injured. J Surg Res. 2003;109(2):144-8.

20. de Grooth H-J, Manubulu-Choo W-P, Zandvliet AS, et al. Vitamin C pharmacokinetics in critically III patients: a randomized trial of four IV regimens. Chest. 2018;153(6):1368-77.

21. Levine M, Rumsey SC, Daruwala R, Park JB, Wang Y. Criteria and recommendations for vitamin C intake. JAMA. 1999:281(15):1415-23.

22. Padayatty SJ, Sun H, Wang Y, et al. Vitamin C pharmacokinetics: implications for oral and intravenous use. Ann Intern Med. 2004;140(7):533-7.
23. Fowler AA, Syed AA, Knowlson S, et al. Phase I safety trial of intravenous ascorbic acid in patients with severe sepsis. J Transl Med. 2014;12:32.

24. Jackson TS, Xu A, Vita JA, Keaney JF. Ascorbate prevents the interaction of superoxide and nitric oxide only at very high physiological concentrations. Circ Res. 1998;83(9):916-22.

25. May JM. Vitamin C transport and its role in the central nervous system. Subcell Biochem. 2012:56:85-103.

26. Harrison FE, May JM. Vitamin C function in the brain: vital role of the ascorbate transporter SVCT2. Free Radic Biol Med. 2009:46(6):719-30.

27. Buehner M, Pamplin J, Studer L, et al. Oxalate nephropathy after continuous infusion of high-dose vitamin $\mathrm{c}$ as an adjunct to burn resuscitation. J Burn Care Res. 2016;37(4):e374-379.

28. Muhlhofer A, Mrosek S, Schlegel B, et al. High-dose intravenous vitamin C is not associated with an increase of pro-oxidative biomarkers. Eur J Clin Nutr. 2004;58(8):1151-8

29. Nathens AB, Neff MJ, Jurkovich GJ, et al. Randomized, prospective trial of antioxidant supplementation in critically ill surgical patients. Ann Surg. 2002;236(6):814-22

30. Stephenson CM, Levin RD, Spector T, Lis CG. Phase I clinical trial to evaluate the safety, tolerability, and pharmacokinetics of high-dose intravenous ascorbic acid in patients with advanced cancer. Cancer Chemother Pharmacol. 2013;72(1):139-46.

31. Hoffer LJ, Levine M, Assouline S, et al. Phase I clinical trial of i.v. ascorbic acid in advanced malignancy. Ann Oncol. 2008;19(11):1969-74.

32. Monti DA, Mitchell E, Bazzan AJ, et al. Phase I evaluation of intravenous ascorbic acid in combination with gemcitabine and erlotinib in patients with metastatic pancreatic cancer. PLoS ONE. 2012;7(1):e29794.

33. Carr AC, Rosengrave PC, Bayer S, Chambers S, Mehrtens J, Shaw GM Hypovitaminosis C and vitamin C deficiency in critically ill patients despite recommended enteral and parenteral intakes. Crit Care. 2017:21(1):300

34. Polidori MC, Mecocci P, Frei B. Plasma vitamin C levels are decreased and correlated with brain damage in patients with intracranial hemorrhage or head trauma. Stroke. 2001;32(4):898-902.

35. Luo M, Fernandez-Estivariz C, Jones DP, et al. Depletion of plasma antioxidants in surgical intensive care unit patients requiring parenteral feeding: effects of parenteral nutrition with or without alanyl-glutamine dipeptide supplementation. Nutrition. 2008;24(1):37-44.

36. Marik PE, Khangoora V, Rivera R, Hooper MH, Catravas J. Hydrocortisone, vitamin $\mathrm{C}$, and thiamine for the treatment of severe sepsis and septic shock: a retrospective before-after study. Chest. 2017;151(6):1229-388.

37. Reynolds PS, Fisher BJ, McCarter J, et al. Interventional vitamin C: A strategy for attenuation of coagulopathy and inflammation in a swine multiple injuries model. J Trauma Acute Care Surg. 2018;85(1S Suppl 2):S57-S67.

38. Sanford K, Fisher BJ, Fowler E, Fowler AA, Natarajan R. Attenuation of red blood cell storage lesions with vitamin C. Antioxidants (Basel). 2017;6(3):E55

39. Mohammed BM, Fisher BJ, Kraskauskas D, et al. Vitamin C promotes wound healing through novel pleiotropic mechanisms. Int Wound J. 2016;13(4):572-84.

40. Barichello T, Machado RA, Constantino L, et al. Antioxidant treatment prevented late memory impairment in an animal model of sepsis. Crit Care Med. 2007;35(9):2186-90.

41. Haywood-Watson RJ, Holcomb JB, Gonzalez EA, et al. Modulation of syndecan-1 shedding after hemorrhagic shock and resuscitation. PLoS ONE. 2011:6(8):e23530.

42. Johansson PI, Henriksen HH, Stensballe J, et al. Traumatic endotheliopathy: a prospective observational study of 424 severely injured patients. Ann Surg. 2017:265(3):597-603.

43. Wei S, Gonzalez Rodriguez E, Chang R, et al. Elevated syndecan-1 after trauma and risk of sepsis: a secondary analysis of patients from the pragmatic, randomized optimal platelet and plasma ratios (PROPPR) Trial. J Am Coll Surg. 2018:227(6):587-95.

44. Fisher BJ, Seropian IM, Kraskauskas D, et al. Ascorbic acid attenuates lipopolysaccharide-induced acute lung injury. Crit Care Med. 2011;39(6):1454-60

45. Fisher BJ, Kraskauskas D, Martin EJ, et al. Mechanisms of attenuation of abdominal sepsis induced acute lung injury by ascorbic acid. Am J Physiol Lung Cell Mol Physiol. 2012;303(1):L20-32. 
46. Berger MM, Soguel L, Shenkin A, et al. Influence of early antioxidant supplements on clinical evolution and organ function in critically ill cardiac surgery, major trauma, and subarachnoid hemorrhage patients. Crit Care. 2008;12(4):R101.

47. Tanaka H, Matsuda T, Miyagantani Y, Yukioka T, Matsuda H, Shimazaki S. Reduction of resuscitation fluid volumes in severely burned patients using ascorbic acid administration: a randomized, prospective study. Arch Surg. 2000;135(3):326-31.

48. Dubick MA, Williams C, Elgjo Gl, Kramer GC. High-dose vitamin C infusion reduces fluid requirements in the resuscitation of burn-injured sheep. Shock. 2005;24(2):139-44.

49. Barbosa E, Faintuch J, Machado Moreira EA, et al. Supplementation of vitamin $E$, vitamin $C$, and zinc attenuates oxidative stress in burned children: a randomized, double-blind, placebo-controlled pilot study. J Burn Care Res. 2009;30(5):859-66.

50. Kochanek PM, Dixon CE, Shellington DK, et al. Screening of biochemical and molecular mechanisms of secondary injury and repair in the brain after experimental blast-induced traumatic brain injury in rats. J Neurotrauma. 2013;30(11):920-37.

51. Arun P, Rittase WB, Wilder DM, Wang Y, Gist ID, Long JB. Defective methionine metabolism in the brain after repeated blast exposures might contribute to increased oxidative stress. Neurochem Int. 2018;112:234-8.

52. Huang J, Agus DB, Winfree CJ, et al. Dehydroascorbic acid, a blood-brain barrier transportable form of vitamin C, mediates potent cerebroprotection in experimental stroke. Proc Natl Acad Sci USA. 2001;98(20):11720-4.

53. Mack WJ, Mocco J, Ducruet AF, et al. A cerebroprotective dose of intravenous citrate/sorbitol-stabilized dehydroascorbic acid is correlated with increased cerebral ascorbic acid and inhibited lipid peroxidation after murine reperfused stroke. Neurosurgery. 2006;59(2):383-8 (discussion 383-388).

54. Ishaq GM, Saidu Y, Bilbis LS, Muhammad SA, Jinjir N, Shehu BB. Effects of a-tocopherol and ascorbic acid in the severity and management of traumatic brain injury in albino rats. J Neurosci Rural Pract. 2013;4(3):292-7.

55. Yan M, Yang M, Shao W, et al. High-dose ascorbic acid administration improves functional recovery in rats with spinal cord contusion injury. Spinal cord. 2014;52(11):803-8.

56. Sajja RK, Prasad S, Tang S, Kaisar MA, Cucullo L. Blood-brain barrier disruption in diabetic mice is linked to Nrf2 signaling deficits: Role of $A B C B 10$ ? Neurosci Lett. 2017;653:152-8.

57. Zhao J, Moore AN, Redell JB, Dash PK. Enhancing expression of Nrf2driven genes protects the blood brain barrier after brain injury. J Neurosci. 2007;27(38):10240-8.

58. Kelly PJ, Morrow JD, Ning M, et al. Oxidative stress and matrix metalloproteinase-9 in acute ischemic stroke: the Biomarker Evaluation for Antioxidant Therapies in Stroke (BEAT-Stroke) study. Stroke. 2008;39(1):100-4.

59. Allahtavakoli M, Amin F, Esmaeeli-Nadimi A, Shamsizadeh A, KazemiArababadi M, Kennedy D. Ascorbic acid reduces the adverse effects of delayed administration of tissue plasminogen activator in a rat stroke model. Basic Clin Pharmacol Toxicol. 2015;117(5):335-9.
60. Guo M, Cox B, Mahale S, et al. Pre-ischemic exercise reduces matrix metalloproteinase-9 expression and ameliorates blood-brain barrier dysfunction in stroke. Neuroscience. 2008;151(2):340-51.

61. Lin J-L, Huang Y-H, Shen Y-C, Huang H-C, Liu P-H. Ascorbic acid prevents blood-brain barrier disruption and sensory deficit caused by sustained compression of primary somatosensory cortex. J Cereb Blood Flow Metab. 2010;30(6):1121-36.

62. Smith SL, Andrus PK, Zhang JR, Hall ED. Direct measurement of hydroxyl radicals, lipid peroxidation, and blood-brain barrier disruption following unilateral cortical impact head injury in the rat. J Neurotrauma. 1994;11(4):393-404.

63. Vagnozzi R, Marmarou A, Tavazzi B, et al. Changes of cerebral energy metabolism and lipid peroxidation in rats leading to mitochondrial dysfunction after diffuse brain injury. J Neurotrauma. 1999;16(10):903-13.

64. Putzu A, Daems A-M, Lopez-Delgado JC, Giordano VF, Landoni G. The effect of vitamin C on clinical outcome in critically ill patients: a systematic review with meta-analysis of randomized controlled trials. Crit Care Med. 2019;47(6):774-83.

65. Maas AIR, Murray G, Henney H, et al. Efficacy and safety of dexanabinol in severe traumatic brain injury: results of a phase III randomised, placebocontrolled, clinical trial. Lancet Neurol. 2006;5(1):38-45.

66. Marshall LF, Maas Al, Marshall SB, et al. A multicenter trial on the efficacy of using tirilazad mesylate in cases of head injury. J Neurosurg. 1998;89(4):519-25.

67. Muizelaar JP, Marmarou A, Young HF, et al. Improving the outcome of severe head injury with the oxygen radical scavenger polyethylene glycol-conjugated superoxide dismutase: a phase II trial. J Neurosurg. 1993;78(3):375-82.

68. Wright $D W$, Yeatts $S D$, Silbergleit $R$, et al. Very early administration of progesterone for acute traumatic brain injury. N Engl J Med. 2014:371(26):2457-66.

69. Razmkon A, Sadidi A, Sherafat-Kazemzadeh E, et al. Administration of vitamin $C$ and vitamin $E$ in severe head injury: a randomized double-blind controlled trial. Clin Neurosurg. 2011;58(Journal Article):133-7.

70. Siqueira IR, Elsner VR, Leite MC, et al. Ascorbate uptake is decreased in the hippocampus of ageing rats. Neurochem Int. 2011;58(4):527-32.

71. Moor E, Shohami E, Kanevsky E, Grigoriadis N, Symeonidou C, Kohen R. Impairment of the ability of the injured aged brain in elevating urate and ascorbate. Exp Gerontol. 2006;41(3):303-11.

72. Carr A, Wohlrab C, Young P, Bellomo R. Stability of intravenous vitamin C solutions: a technical report. Crit Care Resusc. 2018;20(3):180-1.

73. Wilson JX, Jaworski EM, Kulaga A, Dixon SJ. Substrate regulation of ascorbate transport activity in astrocytes. Neurochem Res. 1990;15(10):1037-43.

74. Vera JC, Rivas Cl, Fischbarg J, Golde DW. Mammalian facilitative hexose transporters mediate the transport of dehydroascorbic acid. Nature. 1993;364(6432):79-82. 